\title{
Cerebral Vein Thrombosis
}

National Cancer Institute

\section{Source}

National Cancer Institute. Cerebral Vein Thrombosis. NCI Thesaurus. Code C132727.

The formation of a blood clot in a cerebral vein. 